\title{
UPACARA UA PUA SEBAGAI MEDIA DAKWAH DAN SYIAR ISLAM PADA PENYEBARAN AGAMA ISLAM DI BIMA
}

\author{
Asbah \\ Pendidikan Bahasa Inggris, Universitas Muhammadiyah Mataram, aambalawi@ gmail.com
}

\section{INFO ARTIKEL}

RiwayatArtikel:

Diterima: 06-04-2017

Disetujui: 07-06-2017

\section{Kata Kunci:}

1. Upacara,

2. Ua Pua

3. Media

4. Dakwah dan Syiar Islam

\begin{abstract}
ABSTRAK
Penelitian ini bertujuan untuk mengetahui proses pelaksanaan upacara $\mathrm{Ua}$ Pua dijadikan media dakwah oleh masyarakat bima Metode yang digunakan yaitu deskriptif kualitatif. Teknik pengumpulan data melipu observasi, wawancara, dokumentasi. Hasil Penelitian menjukkan bahwa pada hakikatnya upacara Ua Pua merupakan media dakwah guna meningkatkan keimanan dan ketakwaan ummat serta menjadikan al-qur'an dan sunnah rasul sebagai pedoman hidup Masyarakat bima denga cara diawali dengan dzikir maulid yang berlangsung pada malam hari yang diikuti oleh majelis adat dana mbojo kemudian beberapa hari kemudian barulah upacara ua pua digelar di istana bima, dengan tujuan untuk mengormati para ulama dari makassar yang telah mengajarkan islam kepada masyarakat bima.

Abstract: This study aims to determine the process of implementation of Ua Pua ceremony made daakwah media by the community bima The method used is descriptive qualitative. Data collection techniques include observation, interviews, documentation. The results showed that in essence Ua Pua ceremony is a medium of propaganda in order to increase the faith and piety of the ummah and make al-qur'an and sunnah rasul as the life guidance of the community of premises premises begins with the dhikr maulid which takes place at night followed by the customary council funds mbojo then a few days later then ua pua ceremony held at the palace bima, with the aim to honor the scholars of Makassar who have taught Islam to the community of bima.
\end{abstract}

\section{A. LATAR BELAKANG}

Pada abad 12 masehi,pamor pemerintah Islam yang berpusat di Bagdad, Kian lemah. Mesir,Syiria,Iran dan Afganistan mulai melepaskan diri dari ikatan Bagdad. Pada kurun waktu yang sama ummat Islam sedang dilanda bencana,diserang oleh tentara salib dari barat dan tentara tatar dari timur. Dalam suasana yang mencekam Sultan Salahudin Al Ayub seorang raja Islam terbesar beliau menjadi contoh bagi ummat Islam dari zamannya,terutama karena taatnya pada agama (H.J. Van Den Berg,1952)

Menurut Sultan Salahudin Al Ayub,kelemahan ummat Islam pada masa itu,karena mereka sudah mulai meniggalkan Al-qur'an dan sunah rasul karena itu beliau berusaha keras untuk menyadarkan ummat atas kelemahannya. Salah satu metode dan pendekatan yang beliau lakukan adalah melakukan upacara peringatan hari maulid nabi Muhammad SAW pada setiap tanggal 12 rabiul awal. Upacara itu digelar pula beragam seni budaya
Islam, seperti dzikirmarhaban dan Barjanji(Barjanji adalah seorang sejarawan yang menulis sejarah hidup nabi Muhammad, yang hidup sezaman dengan Sultan Salahuddin Al Ayub.) Sejarah hidup Rasullullah yang ditulis oleh barjanji dinggap sebagai karya sejarah terbaik pada zamannya.

Metode serta pendekatan melalui maulid,berhasil menyadarkan ummat Islam.Mulai saat itu semangat jihad serta ukhuwah islamiyah dikalangan ummat hidup kembali.Sultan Salahuddin Al Ayub berhasil mengalahkan tentara Salib dan tentara Tatar dan mulai saat itulah Upacaramaulid dikenal masyarakat Islam diseantero jagad raya.DiDana Mbojo (Bima) upacara maulud nabi dirangkaikan dengan upacara adat yaitu upacara $U a$ Pua.Upacara adatUa Puamerupakan warisan budaya Islam yang terwarisi turun temurun selama berabad-abad upacara yang spektakuler dimasa lalu itu kini terus dilaksanakan oleh Majelis Adat Dana Mbojo (Bima). 
Dalam perkembangan sejarah Bima, upacara $U a$ Puadilaksanakan pertama kali pada masa pemerintahan Sultan Abdul Khair Sirajuddin, Sultan Bima kedua(16401682). Sejak itu Ua Pua ditetapkan sebagai perayaan rutin kesultanan Bima yang dikenal dengan Rawi Ma Tolu Kali samba'a(upacara besar yang dilaksanan dalam tiga kali setahun).

Sejak itu pelaksanaan Ua Puadiisi dengan beragam kegiatan Seni Budaya dan Agama. Berbagai atraksi kesenian tradisional dilaksanakan selama sepekan,demikian pula kegiatan keagamaan seperti tadarusan,dzikir dan doa,serta ceramah agama.Sehingga Ua Pua benar-benar melekat dalam jiwa masyarakat Bima.Berdasarkan eksistensi Ua Puayang telah diuraikan di atas, hendaknya ada usaha mengembangkan dan melestarikan budaya tradisi,adat istiadat Indonesia khusunya upacara Ua Pua yang menarik, untuk dapat diketahui dan dijadikan bahan penelitian.

Guna menyukseskan perayan upacara $U a$ Pua tidaklah terlepas dari perhatian dan semangat masyarakat dalam mempersiapkan perayaan upacara Ua Pua. Karena sakral upacara adat tersebut peneliti ingin mengetahui makna-makna yang terkandung dalam acara tersebut sehingga peneliti mengangkat judul "Ua Pua Sebagai Media Dakwah Dan Syiar Islam Pada Penyebaran Agama Islam di Bima”.

\section{B. METODE PENELITIAN}

Dalam penelitian ini pendekatan yang digunakan adalah metode kualitatif. Mengingat data yang dikumpulkan berupa data tertulis atau lisan dari orangorang perilaku yang dapat diamati. Penelitian kualitatif adalah penelitian yang menghasilkan data Deskriptif berupa kata-kata tertulis atau lisan dari orang-orang dan perilaku yang dapat diamati, (Muktar, 2009:30). Menggunakan metodeKualitatif penelitian dapat memusatkan perhatiannya pada masalah yang dihadapi untuk mendapatkan data yang sebenarnya. Sebagaimana riilnya dilapangan yaitu data tentang upacara Ua Pua sebagai media dakwah dan Syiar Islam Di Bima

\section{HASIL DAN PEMBAHASAN}

\section{Hasil Penelitian}

Pada hakikatnya Asi Mbojo adalah sebuah istana kesultanan Bima merupakan salah satu tinggalan arkeologi, Bangunan berlantai dua hasil perpaduan arsitektur asli Bima dan Belanda ini menggantikan bangunan sebelumnya yang dibangun pada abad ke-19 M yang awalnya merupakan tempat tinggal Raja-raja Bima. Dalam perkembanganya Istana ini pernah beberapa kali berubah fungsi antara lain : sebagai barak tentara, kantor ruang kerja dan terakhir (saat ini) sebagai Museum Asi Mbojo yang berfungsi sebagai tempat penyimpanan bendabenda peninggalan kerajaan dan kesultanan. Dari istana Asi Mbojo ini peneliti dapat mengungkapkanUa Puasebagai media dakwah dan syiar Islam ini khususnya pelaksanaan upacara Ua Pua itu dan prosesi upacaraUa Puaitu sendiri.

Bangunan yang pernah menjadi istana raja-raja Bima ini mampu bercerita banyak tentang masa lalu moyang orang Bima yang legendaris. Di sebelah timur areal istana berdiri Masjid Agung Bima. Dulu namanya Masjid Agung Al-Muwahidin. Sebelah barat adalah lapangan Taman kota yang dulunya adalah lapangan sepak bola. Selebihnya adalah toko-toko, losmen-losmen dan pelabuhan laut. Asi Mbojo di masa jayanya tidak sepi dari kegiatan sehari-hari kesultanan. Walaupun saat ini tersiasia kalau dibandingkan dengan Museum Samparaja yang terletak kira-kira $2 \mathrm{~km}$ sebelah timur, peranan Asi Mbojo sangat ramai dikunjungi oleh peneliti ataupun baik secara formal maupun non formal, pada masa lalu Asi Mbojo merupakan tempat sakralyang menjadi pusat pemerintahan, seni dan budaya, pusat penyiaran Islam dan Pengadilan Hadat. Istana atau Asi dalam Bahasa Bima dikenal oleh masyarakat Bima pada sekitar abad ke-11 M.

Konsepsi tata letak bangunan istana tidak jauh berbeda dengan Istana lain di tanah Air. Istana menghadap ke barat. Di depannya terdapat tanah lapang atau alunalun namanya Serasuba. Di sinilah raja tampil secara terbuka didepan rakyat di saat-saat tertentu, misalnya saat diselenggarakan upacara-upacara penting atau perayaan hari besar keagamaan. Serasuba juga menjadi arena latihan pasukan kesultanan. Di sebelah alun-alun terdapat 
sebuah bangunan masjid, sebagai sarana kegiatan ritual keagamaan (Islam). Kini masjid itu bernama Masjid Sultan.

Untuk memberi kesan sebagai bangunan monumental, Istana bisa dipandang dari empat penjuru angin. Tampaknya pembangunan Istana memperhatikan konsepsi filosofi sebuah istana yang di dalamnya menyiratkan kesatuan unsur pemerintahan, agama dan rakyat (masyarakat). Bersamaan dengan berakhirnya masa kesultanan pada tahun 1952 M, maka berakhirlah peranan Asi Mbojo sebagai pusat pemerintahan, pusat pengembangan seni dan budaya, pusat penyiaran Islam dan pusat pengadilan hadat. Kini bangunan tersebut menjalani fungsi yang baru sebagai museum bagi barangbarang peninggalan raja-raja dan sultan-sultan Bima.

Di Museum ini juga terdapat tempat penyimpanan benda-benda peninggalan kesultanan Bima. Antara Ruangan bagian timur tersimpan baju adat tari Toja. Ada juga Baju adat Tari Kanja dan baju kebesaran Kerajaan Bima. Pakaian itu digunakan saat upacara Hanta Ua Pua. Pakaian adat gelarang dan cara adat camat kala itu juga tersimpan.

Di ruangan sebelah barat tersimpan alat dapur dari perunggu, peralatan songket, kebaya emas yang dibuat pada abad 16 M. Meja sisa peninggalan Kesultanan Bima, foto Sultan Ibrahim dan Sri Sultan Ibrahim dan Sultan Muda Muhammad Salahuddin masih tersimpan. Di bagian lain ruang museum itu juga, lain, terdapat Pasapu Sutra hasil sulaman dari benang Toha Toji, Songo Waru, tulisan Arab Melayu, contoh pakaian adat pengantin, dan ceret kuningan asli sisa peninggalan Kesultanan.

Posisi tempat menyimpan Al-Quran masa Kesultanan pada abad ke 17 M masih utuh dan Cap dari Belanda. Banyak lagi koleksi lainnya. Di ruangan bagian selatan, tersimpan silsilah kerajaan Bima, filsafat Pemerintah Kesultanan Alat musik tradisional Bima juga masih ada, seperti gendang dan gong. Alat musik itu biasa dimainkan pada masa kerajaan. Alat-alat rumah tangga seperti guci, piring kecil dan lainnya menjadi bagian dari koleksi museum Samparaja. Sayang, rupanya museum ini tak hanya jarang dikunjungi masyarakat Bima. Namun, Pemerintah Daerahpun kurang memerhatikannya. Tak ayal pengelolaannya pun kurang maksimal disini peneliti mengalami kesulaitan untuk mendapatkan data karna pengurus jarang berada di museum. Mungkin karena dianggap museum yang dikelola oleh yayasan. Padahal apa yang tersimpan di dalamnya, menjadi bagian dari keberadaan Dana Mbojo (tanah bima)

\section{Pembahasan}

Dalam proses perayaan $U a$ Pua, terdapat rangkaian acara yang dilaksanakan selama sepekan yang di awali dengan pergelaran berbagai atraksi kesenian di lapangan Sera Suba yaang berada tepat di depan istana bima serta upacara inti yaitu jiki molu yang dilaksanakan pada malam hari sebelum perayaan Ua Pua dan proses inti perayaan Ua Pua.

\section{a) Dzikir Maulid (jiki molu)}

Pada malah hari berlangsung Dzikir maulid di Istana Bima yang diikuti oleh majelis adat Dana Mbojo, pejabat pemerintahan serta masyarakat umum. Dzikir ini diadakan untuk memperingati hari maulid nabi besar nabi Muhammad SAW, sembari dzikir berlangsung oleh beberapa orang melakukan kegiatan pengirisan daun pandan untuk menbuat "bunga bareka" yaitu panda yang dicampur dengan kembang-kembang dan wangi-wangian yang akan dibagikan kepada peserta Dzikir dan maulid.

Dalam acara itu juga berlangsung acara adat weha tau apa yaitu perjamuan kue apam yang dimakan dengan opor serta minum serbat. Setiap pejabat mempunyai satu perangkat hidangan yang ditata di atas talam dan du tutup dengan tonggo apa, penataan kue apam diatur menurut peringkat kepangkatan masing-masing pejabat dalam persidangan juga berdasarkan pangkatnya, perangkat hidangan ini kemudian dibawa ke rumah masing-masing dan kemudian peneutupan acara tersebut ditandai dengan membagi bunga rampai kepada hadirin.(Malingi Alan, 2010: 34)

\section{b) Rangkaian Acara Pada Upacara Ua Pua}

Lazimnya pada upacara Ua Pua dilaksanakan pada jam:

1) Jam 07.00: utusan sultan yang terdiri dari tokoh-tokoh adat, anggota laskar kesultanan, beserta penari Lenggo Mbojo menjemput penghulu melayu dikediamannya di kampung melayu.

2) Jam 08.00: penghulu melayu bersama romnbongan berangkat dari kampung melayu menuju istana Bima yang ditandai bunyi meriam (sekarang sudah tidak 
bunyi meriam). Adapun tata urut rombongan adalah sebagai berikut: 1). Pasukan jara wera yang merupakan pasukan pengawal pembukaan jalan 2). Kemudiandisusul pasukan jara sara,u 3). Dan yang menyusul dibelakangnya adalah anggota laskar suba $n a^{\prime} e$ dan penari Sere yang merupakan gabungan dari anggota pasukan elit kesultanan. Diikuti oleh dua orang penari Sere yaitu jenis tari perang yang dimainkan laskar kesultanan 4). Setelah itu adalah romgbongan pengusung Uma Lige (mahligai) 5). Baru dibelakangnya adalah rombongan pemuka adat melayu dan pemuka adat mbojo.

3) Jam 09.00: rombongan penghulu melayu tiba di istana bima yang disambut dengan: 1).tari Kanja, tari Sere, dan Mihu 2). Kemudian penghulu menyerahkan Ua Pua kepada sultan sebagai simbol kesepakatan penghulu melayu (ulama) dengan sultan bersama seluruh rakyat Dana Mbojountuk mempelajari dan memahami serta mengamalkan isi Al-qur'an dalam kehidupan berbangsa dan bernegara demi terwujudnya kehidupan bermasyarakat mbojo yang islami 3). Sultan bersama penghulu melayu duduk berdampingan di tempat yang sudah disediakan sebagai lambang keharmonisan hubungan ulama dan umara 4). Tari Lenggo Ua Pua, yaitu merupakan perpaduan lenggo melayu yang dimainkan ramaja pria dan Lenggo Mbojo dimainkan remaja putri, sebagai simbol kesamaan visi dan misi masyarakat melayu dan masyarakat mbojo dalam kehidupan beragama, berbangsa dan berbegara 5).kemudian yang terkahir setelah upacara selesai bunga dolu yang bejumlah 99 tersebut dibagi-bagikan kepada hadirin.

Didalam proses perayaan peryaan $U a$ Pua terdapatperlengkapan dan atraksi upacara yang selalu melekat pada setiap perayaan Ua Puadisamping sebagai ajang hiburan juga sebagai dan tontonan untuk masyarakat bima yang menyaksikan perayan upacara $U a$ Pua, perlengkapan dan atraksi itu yaitu:

1) Uma Lige

Berbentuk rumah Allah tempat beribadah pendidikan dan kegiatan Dakwah bagi umat Islam. Didalamnua duduk penghulu melayu sebagai lambang penghormatan kepada ulama sebagai pewaris Nabi yang akan membimbing umat berdasarkan Al-qur'an, Sunah Rasul dan Ijtihad. Selain itu di dalam mahligai juga disertakan perangkat Ua Pua yang berisi Al-qur'an untuk diserahkan kepada sultan serta didampingi oleh penari Lenggo Ua Pua.

Didalam perjalanan ini penari terus menari diatas Uma Lige, di satu tempat yang telah di tentukan, 44 orang pengangkat Uma Kalei diganti oleh regu lain, demikian seterusnya hingga sampai Pagar Utara Istana. Kedua, bedil diletuskan lagi, Ratoyang memimpin rombongan segera maju, naik tangga menghadap sultan dan mihu kemudian mundur dan mengatur rombongannya. Mihu adalah acara penghormatan kepada sultan untuk melaporkan bahwa upacara dimulai. Kemudian pasukan Jara Wera memacu kudanya menuju Istana dan keluar melalui lawa se (gerbang timur), disusul oleh Jena Wera, maju menuju istana sambil memainkan kudanya Sara'u Jara.Rato Renda yang nenunggu di pelataran istanapun melakukan tari Kanja, tari ini adalah tari perang yang dilakukan panglima perang kesultanan, berbagai pergerakan panglima ini tanda bagi rombongan yang datang.

Setindak demi setindak Rato Renda menuju Istana, memberi hormat, kemudian mundur bersamaan itu angguru yang datang dengan rombongan memulai gerakan Sere, disambut oleh angguru yang menunggu di istana. Mereka yang datang secara perlahan mendekat di Istana yang diikutu oleh rumah kalei dengan pengiringannya. Setelah di depan istana para angguru mengahiri Sere, mereka memberi hormat kepada sultan dan juga rato renda juga menghakhiri tariannya.

Uma Kalei yang berada di depan Istana diputarputar kemudian diturunkan, penghulu serta petugas pemayunngan diturunkan mereka menaiki tangga Istana diikuti para penari dan angguru Mpa'a berikut Ua Pua yang diusung dalam Uma Kalei, Ua Pua diturunkan dari usung lalu diangkaat ke ruang Istana untuk diserahkan kepada sultan oleh penghulu.

Usai penyerahan Ua Pua, penghulu dipersilahkan duduk bersama para hadirin. Para penari masuk ke ruang Istana untuk beristrahat sejenak. Tim gendang yanng tadinya ikut dalam rombongan kampung melayupun ikut naik dari pintu timur dan duduk di tempat yang telah ditentukan 
Tahap berikutnya, setelah istrahat sejenak, dIpertunjukkan tari yang dibawa di atas Uma Kalei yaitu Lenggo Mbojo oleh penari putri selesai pertunjukkan tari, Bunga Dolu dibagikan kepada hadirin. Dan selesai puncak acara yang diselenggarakkan pada pagi hari hingga siang hari itu sorenya seluruh kesenian, baik kesenian rakyat maupun keraton yang dibawakan oleh laskar kesultanan dan yang tergolong keturunan melayu, dipergelarkan di depan Istana acara ini berlangsung hingga matahari terbenam.

\section{2) Bunga Dolu}

Di dalam Uma Kalei terdapat sebuah benda berbentuk segi empat panjang yang diatur secara artistik, benda itu 99 Bunga Dolu (bunga telur). Bunga telur terbuatdari telur ayam yang dibungkus dengan kertas minyak yang beraneka warna. Tangkainya terbuat dari kayu atau bambu panjang yang berukuran $30 \mathrm{~cm}$ dan ditancapkan pada wadah segi empat bersama sirih pinang dan kitab Suci Al-qur'an sebagai kitabullah benda inilah yang dikelilingi oleh para penari.

Empat penari pria dan empat penari yang terus menari mengililingi benda di dalam Uma Kalei, melambangkan bahwa Islam bukan agama yang tidak menghargai seni melainkan menempatkan seni sebagai media untuk menyampaikan dakwah.

Penghulu melayu berpakaian kebesaran dan dipayungi, duduk di bagian depan Uma Kalei menyerahkan Uma Kalei dan menyerahkan Bunga Dolu dan Al-qur'an kepada sultan. Hal ini mengingatkan akan guru-guru serta Mubaliq minangkabau yang membawa Islam ke Bima, mereka dipayungi berarti di muliakan dan dihormati.

3) Tari Lenggo

Pada zaman dahulu, Istana Bima atau ASI mbojotidak hanya berfungsi sebagai pusat pemerintahan tetapi juga merupakan pusat seni budaya tradisional. Pada masa kesultanan Abdul Khair Sirajuddin seni budaya berkembang cukup pesat, salah satu seni tari yang tetap eksis hingga saat ini adalah tari Lenggo

Tari Lenggo ada dua jenis yaitu tari Lenggo Melayu dan tari Lenggo Mbojo, Lenggo Melayu diciptakan oleh seorang Mubaliq dari Pagaruyung Sumatera Barat yang bernama Datuk Raja Lelo pada tahun 1070 H. Tarian ini memang khusus diciptakan untuk upacara Ua Pua dan dipertunjukkan pertama kali di Oi Ule (pantai ule sekarang) dalam rangka memperingati maulid Nabi Muhammad SAW. Lenggo melayu juga dalam bahasa bima disebut lenggo mone karena dibawakan oleh remaja pria.

Terisnpirasi dari gerakan Lenggo melayu, setahun kemudian tepatnya tahun $1071 \mathrm{H}$, Sultan Abdul KhairSirajuddin menciptakan Lenggo Mbojo yang diperankan oleh 4 orang penari remaja perempuan. Lenggo Mbojo juga di sebut Lenggosiwe jadilah perpaduanLenggo Mbojo dan Lenggo melayu yang pada perkembangan selanjutnya dikenal dengan Lenggo Ua Pua.

Tati Lenggo selalu dipertunjukkan pada saat upacara Ua Pua terutama pada saat rombongan penghulu melayu memasuki pelataran Istana. Dua pasang lenggo ini turut mendampingi penghulu melayu selama perjalanan dari kampung melayu menuju Istana Bima di atas Uma Lige.

Tarian ini diringi oleh alunan musik tradisonal Bima seperti dua buah gendang besar(genda na'e), gong, silu (sejenis serunai), serta tawa-tawa. Irama tari lenggo berirama lembut mengikuti aluanan musik yang lembut pula. Gerakkannya pelan dan gemulai tari Lenggo juga warisan masa lalu, titipan keluguan zaman untuk generasinya.

\section{4) Pasukan Jara Sara'u dan Jara Wera}

Sebuah kerajaan yang berpengaruh di wilayahnya Timur Nusantara, Bima memiliki pasukan berkuda atau kavaleri yang cukup tangguh hal ini didukung oleh banyaknya populasi kuda di daerah ini dan juga keahlian masyarakat menunggang kuda. Meskipun kecil kuda-kuda bima cukup tangguh baik untuk kepentingan perang maupun transportasi.

Dalam perayaan Ua Pua, kita akan selalu menyaksikan iring-iringan pasukan berkuda sebagai pengawal pembuka jalan yang mengantar rombongan menuju Istana Bima (ASI MBOJO). Ada dua pasukan kavelerry kerajaan Bima yaitu pasukan Jara Wera dan Jara Sara'u, pada zaman dahulu pada saat rombongan penghulu melayu menuju Istana, di tandai dengan bunyi meriam yang menunjukkan bahwa upacara Ua Pua akan dimulai.

Pasukan Jara Wera dalam sejarahnya adalah pasukan yang memang sebagian besar berasal dari kecematan Wera yang setia membela agama Islam. Seluruh 
pasukan putih sebagai lambang kesucian dan keihklasan dalam membela agama, rakyat, dan negara.

Sedangkan pasukan Jara Sara'u yaitu pasukan berkuda yang terampil menunggang kuda serta mengatur irama gerak langkah kuda. Pasukan ini memiliki keahlian dalam memainkan pedang, tombak, dan keris diatas kuda dan dalam acara seperti Ua Pua mereka menampilkan atraksi dengan cara mengatur hentakan kaki kuda yang seirama dengan alunan gendang dan serunai serta gerakan penari Lenggo.

Para penunggangnya adalah pendekar yang menunjukkan jalan serta mengantar para Datuk yang datang dari Makassar menuju Bima lewat Teluk Bima ketika pertama kali membawa ajaran Islam di kerajaan Bima itulah posisi Jara Wera berada di posisi paling depan. Dibelakang pasukan Jara Weradiikuti oleh Jara Sara'u yaitu pasukan elit berkuda kesultana Bima sebagai pengawal kehormatan. Kuda-kuda ini melakukan atraksi mempertontonkan keterampilan seni menarinya.

5) Sere

Iring-iringan Uma Lige disambut tari Sere yang mengantar uma lige sampai ke tangga istana tari Sere adalah sejenis tari perang yang dimainkan oleh enam orang penari bersama bintara kesultanan bima yang disebut "bumi sumpi" sebagai tanda terjaminnya keamanan dan ketertiban jalannya upacara.

Sambil memegang tombak, para penari Sere mengacungkan tombak dan melangkah menuju tangga Istana yang diiringi musik tambur dan silu(sejenis alat musik tiup khas Bima)

1) Laskar Suba Na'e

Laskar Suba Na'e adalah pasukan prajurit kesultanan bima. Pasukan perang ini membawa peralatan perang berupa tombak dan tameng sebagai simbol kesiapsiagaan pasukan kerjaan mengamankan negeri. Di belakang pasukan laskar pasukan Suba $\mathrm{Na}^{\prime}$ e berjalan Uma Lige yang diiringi oleh keluarga besar kampung melayu, mereka adalah tamu kehormatan dalam upacara Ua Pua tersebut.

\section{2) Tari Kanja dan Mihu}

Tari Kanja yakni tari perang yang dimainkan oleh seorang perwira tinggi kesultanan sebagai pernyataan kesiapan menjaga keaman dan ketertiban jalannya upacara. Sedangkan mihu merupakan pernyataan kesiapan sultan untuk menerima sekaligus memulai perayaan $U a$ Pua.

\section{c) Tujuan Upacara UaPua}

Dalam sebuah perayaan atau acara-acara penting di suatu daerah perayaan-perayan suatu upacara tentu saja memiliki tujuan dan harapan tertentu, khususnya pada masyarakat bima sendiri, disamping itu juga sebagai ajang promosi kepada wisatawan lokal maupun wisata luar.

Setelah masyarakat memahami secara benar dan utuh tentang arti kata Ua Pua, maka perlu ditindak lanjuti dengan upaya mensosialisasikan tujuan yang ingin dicapai melalui pelaksanaan upacara tersebut. Para Ulama melalui Datuk Raja Lelo dan kawan-kawan sebagai perintis pelaksaan upacara adat Ua Pua, telah meluruskan tujuan yang ingin dicapai sebagai berikut :

a. Memperingati dan memuliakan hari kelahiran Nabi BesarMuhammadSAW.

b. Memperingati masuknya Agama Islam dan berdirinya Kesultanan Bima.

c. Menghormati Penghulu Melayu (Datuk gurunya) beserta seluruh kaum keluarga/keturunannya yang berjasa menyebarluaskan Agama Islam di Bima.

Jadi jelas bahwa tujuan pada upacara Ua Pua di atas adalah sebagai penghormatan kepada ulama-ulama atau keturunan melayu yang ada di malayu kota bima yang pernah berjasa menyebarkan ajaran islam kepada masyarakat bima dan sekaligus untuk memperingati hari maulid nabi muhammad SAW serta masuknya agama islam di bima seperti yang dijelaskan oleh 2 informan pada wawancara pada waktu yang berbeda.

Kalau disimak secara cermat tujuan dari upacara Ua Pua dapat disimpulkan bahwa pada hakikatnya Upacara $U a$ Pua merupakan media Dakwah guna meningkatkan keimanan dan ketakwaan umat serta menjadikan AlQur'an dan Sunnah Rasul sebagai pedoman hidup. Selain itu Upacara Ua Pua bisa melahirkan sikap menghargai sejarah, sehingga masyarakat mau berguru kepada sejarah dan menatap kehidupan hari ini demi kejayaan hari esok. Upacara Ua Pua juga merupakan media yang paling efektif bagi Seni Budaya Mbojo yang Islami.Mampu memotifasi seniman dan budayawan untuk menciptakan karya seni 
yang bermutu yang layak dipergelarkan dalam Upacara $U a$ Pua. (Malingi Alan, 2010: 31)

Dan upacara Ua Puatelah berhasil mengobarkan semangat jihad Sultan bersama rakyat. Pada masa itu Kesultanan Bima menjadi pusat penyiaran Islam diwilayah nusantara bagian timur,bersama Makasar dan Ternate. Rakyatnya terkenal taat menjalankan perintah agama.Pada usia tujuh tahun putra-putri mbojo, telah mampu mengkhatam Al-qur'an.Sulit diremukan anggota masyarakat yang tidak biasa mengaji.Perbuatan tercela seperti pencurian,dan perjudian jarang terjadi. (Majelis Adat Dana Mbojo, 2004: 05)

\section{d) Makna Upacara Ua Pua}

Pada ksempatan ini sedikit penulis ini akan memaparkan secara singkat tantang makna yang terkandung dalam pelaksanaa upacara Ua Pua. Menurut bapak hasan ibrahim tokoh adat Dana Mbojo kata Ua Pua berasal dari bahasa melayu "sirih puan" yang berarti wadah untuk menyimpan sirih dan arti secara konotasi kata Ua Pua adalah rangkaian upacara adat untuk memeriahkan hari maulid nabi besar Muhammad SAW yang dilaksanakan sepekan pada saat bulan maulud. Puncak perayaan $U a$ Pua ditandai dengan pennyerahan $U a$ Puayang berisis sebuah kitab suci Al-qur'an oleh penghulu melayu(ulama) kepada sultan yang pada pagi hari tanggal 12 rabiul awal bertempat di Istana Bima. Upacara tersebut merupakan simbol kesepakatan ulama dan sultan bersama seluruh masyarakat untuk menjujung tinggi (mencintai kitab Al-qur'an).

Dengan kata lain Al-qur'an dijadikan sumber hukum serta pedoman dalam kehidupan berbegara dan bermasyarakat, di samping Sunnah Rasul dan ijtihad para ulama(Ijma, Qyias, Dan Urfshaih) sultan bersama rakyat harus menghormati para ulama yang ihklas membimbing mereka ke jalan lurus. Setelah masyarakat memahami secara benar dan utuh tentang arti kata Ua Pua, maka perlu ditindak lanjuti dengan upaya mensosialisasikan tujuan yang ingin dicapai melalui pelaksanan Upacara tersebut. Para ulama melalui Datuk Raja Lelo dan kawankawan sebagai perintis pelaksanaan upacara $U a$ Pua.Upacara Ua Pua juga merupakan media yang paling fektif bagi seni budaya Mbojo yang islami.
Guna memahami substansi upacaraUa Pua secara benar dan utuh penulis meluruskan ejaan (tata tulis) kata Ua Pua (sirih puan). Sebab dalam kenyataanbta ejaan yang dipakai masih beragam, sebagai ada yang menulis dengan ejaan Ua Pua dan ada pula yang menggunakan U'a Pua. Menurut salah satu tokoh adat melayu ejaan yang benar adalah "UaPua" bukan " $U$ 'a Pua"(bapak muhammad ibrahim) tetapi kenyataan masih banyak masyarakat yang mempergunaakan ejaan yang salah (U'a Pua) akibatny lahir konotasi yang keliru. Masyarakat menyangka bahwa upacara Ua Pua sama dengan NE,E U'A (panjat pinang) yaitu salah satu jenis olahraga yang dipopulerkan oleh pembesar belanda pada zaman kolonial untuk dijadikan tontonan kerajaan besar belanda. Ditinjau dari substansi olahraga NE,E U'A dapat merusak perkembangan jiwa anak karena olahraga tersebut menghalalkan segala cara demi mencapa tujuan tanpa mengindahkan nilai etika dan norma, karena itu alangkah baiknya bila kita meninjau kembali keberadaan olahraga NE'E U'A masih banyak olahraga yang bernilai positif bagi perkembangan rohani dan jasmani anak-anak.

\section{SIMPULAN DAN SARAN}

\section{Simpulan}

Tujuan dari ua pua dapat disimpulkan bahwa pada hakikatnya upacara ua pua merupakan media dakwah guna meningkatkan keimanan dan ketakwaan ummat serta menjadikan al-qur'an dan sunnah rasul sebagai pedoman hidup Masyarakat bima. Dan proses pelaksanaan dan maknanya sebaga berikut:

a) Proses pelaksanaan upacara ua pua yaitu yatu proses upacara Ua Pua diawali dengan dzikir maulid yang berlangsung pada malam hari di istana kesultanan bima ASI yatiu tepatnya pada tanggal 12 rabiul awal dan diikuti oleh mejelis adat dana mbojo, serta masyarakat umum, kemudian beberapa hari setelah itu upacara Ua Pua digelar di istana bima dengan dibawanya Uma Lige berisi serumpun bunga telur dan penari lenggo ke istana bima dan menyerahkan alqur'an kepada sultan Bima, sebagai rasa hormat kepada mubaliq makassar yang telah mengajarkan Islam kepada masyarakat bima. 
b) Tujuan dari pelaksaan uapcara Ua Pua di kalangan masayarakat bimayang pertama untuk menghormati para ulama-ulama dari makasar yang telah mengajarkan islam kepada masyarakat bima, kemudian perayaan Ua Pua ini juga untuk memperingati hari lahir nabi besar muhhammad SAW.

c) Makna yang terkandung dalam pelaksanan upacara $U a$ Pua ini yaitu kita bisa lihat setiap rincian acara dan setiap perlengkapan dan peralatan pada upacara memiliki arti dan makna tertentu yang bertujuan untuk menjujung tinggi ajaran islam dapat memberikan gambaran terhadap masyarakat bima tentang ajaran islam dan bagaimana cara menjujung tinggi ajaran islam yang berpedoman kepada la-qur'an dan sunnah rasul kemudian betapa besar peran Ua Pua sebagai media dakwah dan syiar pada masyarakat bima.

\section{Saran}

a) Kepada pemerintah serta segenap unsur jawatan yang berkompoten didaerah disarankan, agar dapat mempromisikan suatu tradisi kebudayaan kepada masyarakat luas terutama upacara hanta $\mathrm{Ua} P u a$.

b) Kepada tokoh masyarakat di daerah Bima, yang telah mencoba mendokumentasikan peristiwa-peristiwa masa lampau daerah Bima, penulis sarankan agar menggiatkan meningkatkan usaha itu untuk mendapatkan peristiwa baru sekitar masa lampau daerah tersebut. Karena tidak sedikit jumlah sumber sejarah daerah yang masih terpendam yang belum diabadikan secara tertulis.

c) Kepada seniman dan budayawan agar dapat memotivasi diri agar dapat berkreasi menciptakan karya seni yang bermutu yang layak dipergelarkan pada saat perayaan upacara ua pua

\section{DAFTAR RUJUKAN}

Amin Ahmad, 1971. Sejarah Bima, Sejarah Pemerintahan Serba Serbi Kebudayaan Bima (Stensil).

Arikunto Suharsimi, 2006. Prosedur Penelitian Suatu Pendekatan Teoritik.Jakarta: Rineka Cipta.

Ashari.A.R, 2013. Teori-teori Masuknya Islam Ke Indonesia, 24 April 2013. Di ambil pada tanggal 28 mei 2013 dari www.jagoips.wordpress.com

Mejelis Adat Dana Mbojo, 2004, UA PUA sebagai Media Dakwah dan Syiar Islam.

Malingi Alan, 2010, Upacara Adat HantaUA PUA, Mataram: Mahani Persada

Muslimmin Hamzah,2004 Ensiklopedia Bima,Lengge, Ternaglobal.
M.Hilir Ismail,1983 Proses islamisasi di Bima, Makalah Seminar Masuknya Islam Di Bima, kanwil depag propinsi NTB, Mataram.

M. Hilir Ismail,2008 Kebangkitan Islam Di Dana Mbojo(Bima).(1540-1950), penerbit Binasti.

Moleong Lexy J, 1988 Metode Penelitan Kualitatif, Remaja Rosdakarya, Bandung.

Naniek I. Taufan, 2012 Warna-Warni Tradisi Sasak Samawa Mbojo, Bima: Museum Sampa Raja Bima

Riyanto, 2006. Pendekatan Kualitatif, Jakarta: Perenial Press

Salim Agus Haji,1967 Riwayat Kedatangan Islam Di Indonesia, Tinta Mas, Jakarta.

Syarawati dan M. Yusuf H.umar, 1986 upacara ua pua di kabupaten bima (pengaruh agama Islam)

Sugiono, 2009. Penelitian Kualitatif. Jakarta: Alfabeta

Tayib Abdullah,1996. Sejarah Dan Mbojo Bima, Jakarta Percetakan Harapan Masa. 